\title{
Life indicators, illness characteristics, and psychosocial concomitants of self-reported multiple chemical sensitivity: A two-year longitudinal study
}

\author{
Pamela Reed Gibson \\ Department of Psychology, James Madison University, Harrisonburg, United States.
}

Correspondence: Pamela Reed Gibson. Address: Department of Psychology, James Madison University, MSC 7704, Harrisonburg, United States. Email: gibsonpr@jmu

Received: September 4, 2013

Accepted: October 24, 2013

Online Published: January 6, 2014

DOI : $10.5430 /$ jnep.v4n3p204

URL: http://dx.doi.org/10.5430/jnep.v4n3p204

\section{Abstract}

Life indicators, illness characteristics, and psychosocial concomitants were measured in a large sample of persons self-reporting multiple chemical sensitivity. Cross-sectional data are presented for 305 persons who responded to written surveys. Examined are employment status, income, relationship status, illness characteristics such as length, severity, and age respondents became sensitive, money spent on physicians and on home alterations, situations reported to cause the initial sensitization, and the psychosocial measures of social support and psychosocial adjustment to illness. In addition, relevant life indicators are re-examined two years later and presented for 209 persons who continued to participate. This paper examines life indicators for persons of four levels of severity of condition and three courses of condition over time.

\section{Key words}

Chemical sensitivity, Multiple chemical sensitivity, Chemical hypersensitivity, Chemical intolerance

\section{I ntroduction}

The problem of self-reported illness from low levels of chemical exposures has been the subject of discussion in the professional literature. Persons who report experiencing this condition, referred to as multiple chemical sensitivity (MCS), chemical sensitivity (CS), chemical intolerance (CI), and other labels report symptoms that span multiple bodily systems, and do not necessarily conform to accepted toxicological principles. The problem has considerable overlap with allergy and asthma, but does not respond to traditional treatment for either ${ }^{[1-4]}$.

Symptoms and incitants of MCS have received considerable attention, but causation had been the subject of some disagreement with some writers suggesting psychological causation ${ }^{[5]}$. However, Bloch and Meggs ${ }^{[1]}$ found that comorbid depression and anxiety in persons with chemical sensitivity were no greater than found in persons with allergy or general medical illness. Similarly, Swoboda ${ }^{[6]}$ found that although persons with emerging conditions including MCS often receive psychological labels, treatments based on these labels are inadequate and patients eventually seek other approaches. Gibson, Elms, and Ruding ${ }^{[7]}$ likewise found that 917 MCS patients rated psychoactive medications such as 
anti-depressants and anti-anxiety meds as being ineffective. It therefore appears more likely that depression is a consequence of the disability as with other chronic illnesses ${ }^{[8]}$. Ternesten-Hasséus and colleagues ${ }^{[4]}$, when discussing sensory hyperreactivity (SHR), a sub-condition of MCS, sum up, "In conclusion, airway symptoms induced by chemicals and scents can be regarded as a chronic condition and may represent an entity of chronic diseases, with persistent symptoms, as reduced HRQL [Health Related Quality of Life], and unchanged long-lasting sensory hyperreactivity” (p. 429).

Symptoms in chemical sensitivity can affect any bodily system including respiratory, digestive, neurological, and musculoskeletal. Gibson and Vogel ${ }^{[9]}$ found tiredness/lethargy, difficulty concentrating, muscle aches, memory difficulties, and long-term fatigue the most commonly cited symptoms in 254 persons with self-reported MCS. Participants in the same study cited pesticides, formaldehyde, fresh paint, new carpets, diesel exhaust, perfumes and air fresheners as causing the most symptomatology. Showing some overlap, Hojo and colleagues ${ }^{[10]}$ found the highest rated incitants to be insecticide, paint/paint thinner, cleaning products, fragrance, nail polish/hair spray, and tobacco smoke with a quarter of patients citing pesticides/agricultural chemicals as initiatory.

The problem is reported in a number of countries. In Sweden $15.6 \%$ of teenagers reported chemical sensitivity ${ }^{[11]}$, and $33 \%$ of adults reported being bothered by strong odors, while $19 \%$ had made behavioral changes as a result ${ }^{[12]}$, In The Netherlands $45 \%$ of persons reported problems with at least one chemical and $27 \%$ from multiple chemicals ${ }^{[13]}$. A German study found that $32 \%$ of persons blamed their health concerns on and $11 \%$ reported immediate reactions from chemical exposure ${ }^{[5]}$. Meggs and colleagues ${ }^{[14]}$ in the US found that $4 \%$ of a rural representative household sample reported illness from chemicals on a daily basis with one third of respondents reporting some illness from exposures to chemicals. Prevalence of chemical sensitivity in the Meggs et al. study equaled that of conventional allergy, and cut across all demographic groups. Caress and Steinemann ${ }^{[15]}$, in a series of studies, found that $11.4 \%$ of the US general population reported sensitivity to fragranced products. Bell and colleagues ${ }^{[16]}$, also in the US found that $66 \%$ of college students reported at least moderately ill feelings from at least one of the following: pesticide, auto exhaust, paint, new carpet, or perfume; and 15\% reported becoming ill from at least four of the five.

A source of pressure to come to some understanding regarding causality and to implement prevention and treatment of chemical sensitivity comes from the seriousness of reactions reported, and from the sometimes very extensive life impacts of living with the condition. Persons reporting MCS often experience challenges and losses occupationally, financially, socially, and in housing and community access ${ }^{[17,18]}$. Problems with medical access ${ }^{[19]}$, diagnosis ${ }^{[17]}$, and relationships with health care providers ${ }^{[20]}$ have been reported. When no clear diagnostic code exists for a condition, legitimacy is denied to the sufferer, as "one must suffer in code in order to be suffering in fact, or one does not suffer at all" ${ }^{[21]}$. Even in emergencies. Engel et al. ${ }^{[19]}$ found that people with MCS could not access medical facilities due to pesticides, petrochemical heating systems, carpets, cleaners, and perfumes on medical personnel. Some persons feared that they would inadvertently become ill as a result of medical interventions and medications. Consequently they delayed or avoided obtaining treatment. Respondents thus avoided general dental work, medications, surgeries, and diagnostics. One woman described being so sensitive to dental anesthetics (even locals) that she suffered from an abscessed tooth for two years. Further, Engel et al. ${ }^{[19]}$ found that respondents reported having general dental work, root canals, and tooth extractions without anesthesia.

Doiron ${ }^{[20]}$ found that the problems with accessing services extended to a variety of agencies and that even health providers who worked with persons with MCS had difficulty understanding and labeling the needs of their clients. The current study was conducted in order to explore differences in life indicators related to level of severity and course of condition over time, and to understand psychosocial concomitants of having MCS. This is the first follow-up study of persons with MCS of which I am aware. 


\section{Method}

\subsection{Participants}

Participants are 305 persons with self-reported MCS who were recruited in the US through newsletters for persons with chemical sensitivities, support groups, a national publication, a national advocacy group (the National Center for Environmental Health Strategies), the Chemical Injury Information Network (CIIN), and physicians' offices.

\subsection{Procedure}

Confidential hard copy questionnaires were gathered from 305 persons. Six months later, a follow-up questionnaire was sent to expand and clarify data collected, and 268 persons responded. Two years later a follow-up survey was conducted with 209 persons willing to participate in further research.

\subsection{Measures}

Questionnaires gathered demographic, descriptive, and psychosocial data using both quantitative and qualitative measures. Respondents provided information that included demographics; occupational status; suicidality, whether or not they had ever lived in unusual circumstances such as tents, trailers, or cars due to their health, whether they had a physician educated regarding MCS, and severity, length, and course of illness. Also included were measures of the psychosocial variables social support and psychosocial adjustment to illness, and qualitative questions regarding access and relationships. At two-year follow-up, respondents were again asked about course of illness, income, relationship and work status, and social support.

Social Support. Perceived social support was measured using part 2 of the Personal Resource Questionnaire 85 (PRQ85) ${ }^{[22]}$, a self-report instrument comprosed of 25 items rated on a 7-point Likert scale. Internal consistency (coefficient alpha) has been reported at .90 with 333 white middle class adults (104 women, 229 men) mean age $=44.2^{[23]}$.

Adjustment to Illness. The Psychosocial Adjustment to Illness Scale Self-Report (PAIS-SR) ${ }^{[24]}$ measures illness adjustment in seven domains: Health Care Orientation, Vocational Environment, Domestic Environment, Sexual Relations, Extended Family Relations, Social Environment, and Psychological Distress. The self-report 46-item scale uses 4-point Likert scales with higher ratings meaning more disruption. Reliability varies between illness groups and norms have been published for lung cancer, renal dialysis, burn, hypertension, cardiac, and mixed cancer groups.

Coding. Respondents were asked about working out of the home (coded 1 for "employed" and 0 for "not employed"). Course of illness was assessed at time one and time two as ("worsened", "stayed the same", "mixed course", or "improved"). In addition, course of illness was measured at time 2 on a 7-point Likert scale that ranged from 'large decline' to 'large improvement'. Severity of condition was assessed at time 1 using a 4-point scale adapted from "E.I. Disability" ${ }^{\text {[25] }}$ (see Table 1).

\subsection{Analyses}

Sample characteristics were examined through SPSS using descriptives, frequencies, $t$-tests, chi-squares, ANOVAS, and a MANOVA. Since this is exploratory research, many relationships among variables were examined. Since multiple univariate tests were conducted, a .01 level of significance was required to help protect against type I error.

This paper describes sample characteristics and presents cross-sectional data on psychosocial adjustment to illness based on the 305 original participants. Initial sensitization data are based on the 268 persons who responded to the 6-month follow-up. Also presented are data on course of illness for persons of various levels of severity of illness as measured at time one, changes in life indicators at 2-year follow-up, and differences between subgroups who reported differing courses 
of illness over the two-year intervening period. These longitudinal data for life indicators and course of illness are based on 209 persons who completed follow-up surveys.

Table 1. Categorical guidelines for levels of disability

\begin{tabular}{|c|c|}
\hline Level & Description \\
\hline Mild & $\begin{array}{l}\text { Able to work. Frequently has many symptoms, some of vague nature. May find petrochemicals and } \\
\text { other environmental exposures such as auto exhausts cigarette smoke, and cleaning materials to be } \\
\text { unpleasant or produce uncomfortable feelings, but able to work effectively. }\end{array}$ \\
\hline Moderate & $\begin{array}{l}\text { Able to work at home or with controlled environment at work place. May have to use gas mask or charcoal mask } \\
\text { and air purifier filter system. Exposure to inciting agents causes acute symptoms which may alter functional } \\
\text { capacity (severe headache, muscle pain, poor concentration, memory loss, etc.). May have to change job or work } \\
\text { conditions if environmental pollution is severe enough. }\end{array}$ \\
\hline Severe & $\begin{array}{l}\text { Unable to work effectively, even with environmental control, using avoidance, masks or filters. On some days, } \\
\text { may be able to work } 30 \text { to } 60 \text { minute shifts several time a day if in a very controlled environment. Reacts to } \\
\text { chemicals such as insecticide, phenols, chlorine, formaldehyde, perfume, petro-chemicals, etc. Has severe mental } \\
\text { and physical symptoms which may or may not clear. Public exposures such as church, post office, movie or } \\
\text { shopping are not tolerated. Visitors to home must clean up significantly. Can usually care for self in a home } \\
\text { situation. May be able to drive if automobile made free of inciting agents, sealed, and has charcoal air filters. Has } \\
\text { difficulty with other family members or guests in home who bring in aggravating exposures on clothing, printed } \\
\text { material, hair, etc. Adversely reacts to many medications. May have to move if existing home has uncontrollable } \\
\text { outdoor pollution, is new and has not outgassed, or has other significant problems of mold, flooring, or other } \\
\text { incitants. Requires a clean room, carpet-free, cleared of inciting agents, special eating and air filtering. Must wear } \\
\text { natural fiber clothing specially laundered. }\end{array}$ \\
\hline Disabled & $\begin{array}{l}\text { Requires assistance to function in rigidly controlled home environment. Reactive symptoms have spread to } \\
\text { virtually all environmental agents including chemicals, foods, pollens, and molds. Has mental and physical } \\
\text { symptoms that are incapacitating, although frequently not structurally described. Total and very restrictive } \\
\text { environmental control required in home and vehicle. Cannot tolerate family or help who have outside exposures } \\
\text { with even small contamination of clothing or hair with odors. Visitors usually are too toxic to be tolerated indoors. } \\
\text { Usually requires several moves to different areas of the country to find tolerable climate which is also chemical } \\
\text { free. May require unusual and extensive measures to make a tolerable clean refuge area to sleep in. Has difficulties } \\
\text { with virtually everything in environment (universal reactor). }\end{array}$ \\
\hline
\end{tabular}

Note. From "E.I. Disability Classification", 1987, The Human Ecologist, No. 35, P. 13. Material relating to food sensitivities was deleted.

\section{Results}

\subsection{Demographics}

Initial respondents were 305 persons ranging in age from 23 to $79(\mathrm{M}=46.8, \mathrm{SD}=10.67), 80.3 \%$ of whom were women. Participants learned of the study from the Chemical Injury Information Network (32\%), the NEEDS newsletter (19\%), the Human Ecologist (the publication of the Human Ecology Action League) (16\%), the National Center for Environmental Health Strategies (7\%), support groups (6\%), physicians (2\%), and other sources (18\%). Ethnicity was reported as Caucasian (92.8\%), Native American (4.9\%), Latina/Latino (1\%), and Asian American (.7\%). Relationship status included married (54\%), divorced or separated (22.6\%), single (15.7\%), living with partner (5.2\%), and widowed (2.6\%). Persons had been affected by MCS for a mean of 15 years, and had become affected at a mean age of 32. Participants rated their conditions as mild (12.8\%), moderate (31.1\%), severe (39.3\%), and totally disabled (15.7\%) according to the categorical descriptions of levels of disability listed in Table 1. Characteristics of the initial and 2-year follow-up samples are listed in Table 2. Still participating in this research at 2-year follow-up were 209 persons (82.3\% women) with a mean age of 47 years. Attrition at follow-up left sample characteristics very similar. 
Table 2. Total Sample Characteristics for 305 initial respondents and 209 continuing participants with Self-Reported Sensitivity to Chemicals

\begin{tabular}{|c|c|c|}
\hline & $\begin{array}{l}\text { Initial Sample } \\
\mathrm{n}=305\end{array}$ & $\begin{array}{l}\text { Longitudinal Sample } \\
\mathrm{n}=209\end{array}$ \\
\hline Gender (\% women) & 80.3 & 82.3 \\
\hline Mean age time 1 & 46.8 & 45.0 \\
\hline \% Caucasian & $92.5^{*}$ & $91.9 * *$ \\
\hline \% Employed time 1 & 31.5 & 34.4 \\
\hline \% Employed time 2 & & 34.0 \\
\hline$\%$ in intimate relationship time 1 & 61.3 & 63.6 \\
\hline$\%$ in intimate relationship time 2 & & 51.7 \\
\hline Personal income time 1 in thousands & 13.3 & 13.9 \\
\hline Personal income time 2 in thousands & & 16.3 \\
\hline Household income time 1 in thousands & 35.7 & 36.9 \\
\hline Household income time 2 in thousands & & 37.2 \\
\hline$\%$ citing 1 sensitizing exposure & 42.3 & 49.0 \\
\hline$\%$ citing pesticide as sensitizer & $27.1^{* * *}$ & $24.5^{* * *}$ \\
\hline Years with MCS at time 1 & 14.4 & 14.7 \\
\hline Age became ill & 32.0 & 32.3 \\
\hline 1-year medical costs in dollars & 5,784 & 5,899 \\
\hline Total medical costs in dollars & 34,783 & 35,258 \\
\hline Cost to make home safer in dollars & 27,816 & 27,974 \\
\hline$\%$ who had doctor educated re: MCS & 72.1 & 73.7 \\
\hline PRQ85 score mean at time 1 & 125.9 & 126.7 \\
\hline PRQ85 score mean at time 2 & & 131.9 \\
\hline PAIS-SR mean score at time 1 & 66.04 & 65.1 \\
\hline
\end{tabular}

* Other groups represented include Native Americans (4.9\%), Latina/Latino (1.0\%), Asian (.7\%), and other (.7\%).

** Other groups represented include Native American (4.8\%), Latina/Latino (1.0\%), Asian (1.0\%), and other (1.0\%).

*** Of those who had one identifiable exposure.

Persons cited working in 75 different occupations before developing MCS. Most commonly cited occupations included homemaker ( $n=29)$; clerical $(n=24)$; student $(n=22)$; teacher $(n=17)$; nurse $(n=15)$; social worker, psychologist or counselor ( $(n=9)$; salesperson $(n=8)$; retail owner $(n=7)$; computer programmer/analyst/software designer $(n=6)$; health care worker $(n=6)$; or manager $(n=6)$.

Of the 268 respondents at 6-month follow-up, 135 suspected that they had been made sensitive by one identifiable exposure, 64 said that they had not, and 67 did not know (2 did not answer this question). Chemical exposures most commonly cited as having induced chemical sensitivity in the 135 persons who attributed their conditions to identifiable exposures included pesticide $(n=35)$ followed by remodeling $(n=13)$ and workplace renovations $(n=8)$. Also cited by five or more persons were new carpet, formaldehyde, and trichloroethylene. Many persons felt that they had become ill from a long series of exposures rather than as a result of an identifiable occurrence.

\subsection{Cross-sectional psychosocial adjustment data for $\mathbf{3 0 5}$ respondents}

Participants had the most life disruption in Social Environment and Vocational Environment with means of 1.72 and 1.84 respectively on 4-point Likert scales. Least disrupted was the Extended Family Relations domain $(M=1.06)$. Domain item means are displayed in Table 3. 
Table 3. Domain Item Means for PAIS-SR

\begin{tabular}{lll}
\hline & & Item \\
\hline Domain & Mean & SD \\
\hline Health Care Orientation & 1.43 & .50 \\
Vocational Environment & 1.84 & .77 \\
Domestic Environment & 1.55 & .59 \\
Sexual Relationships & 1.26 & .75 \\
Extended Family Relationships & 1.06 & .71 \\
Social Environment & 1.72 & .69 \\
Psychological Distress & 1.32 & 1.32 \\
\hline
\end{tabular}

*range 0-3 with higher score $=$ more disruption

PAIS-SR total scores had significant correlations with household income $(r=-.269, p=.000)$, personal income $(r=-.198$, $p=.001)$, self-rating of severity of illness $(r=.356, p=.000)$, an improved course of illness $(r=-.227, p=.000)$, PRQ85 scores at time $1(r=-.550, p=.000)$, and suicidality $(r=.391, p=.000)$, but not with age $(r=.007, p=.899)$, education $(r$ $=-.151, p=.008)$, years ill $(r=-.013, p=.827)$, or gender $(r=-.023, p=.692)$. Inter-correlations between overall PAIS-SR scores and domain scores and other variables are shown in Table 4.

Table 4. Correlations of total pais-sr scores and domain scores with other variables

\begin{tabular}{|c|c|c|c|c|c|c|c|c|}
\hline & $\begin{array}{l}\text { Total } \\
\text { PAIS-SR }\end{array}$ & $\begin{array}{l}\text { Health } \\
\text { Care }\end{array}$ & $\begin{array}{l}\text { Vocation } \\
\text { Domain }\end{array}$ & $\begin{array}{l}\text { Domestic } \\
\text { Domain }\end{array}$ & $\begin{array}{l}\text { Sexual } \\
\text { Domain }\end{array}$ & $\begin{array}{l}\text { Extended } \\
\text { Family }\end{array}$ & $\begin{array}{l}\text { Social } \\
\text { Domain }\end{array}$ & Psychological \\
\hline Education & -.116 & -.088 & -.089 & -.048 & -.034 & -.081 & $-.157 *$ & -.049 \\
\hline $\begin{array}{l}\text { Severity of } \\
\text { Condition }\end{array}$ & $.361^{* * *}$ & -.038 & $.537 * * *$ & $.310 * * *$ & .039 & $.275^{* * *}$ & $.361 * * *$ & .009 \\
\hline $\begin{array}{l}\text { Length of } \\
\text { Illness }\end{array}$ & -.000 & .114 & $-.136^{*}$ & .034 & $.185 *$ & .008 & .086 & -.051 \\
\hline $\begin{array}{l}\text { Personal } \\
\text { Income }\end{array}$ & $-.220 * *$ & -.074 & $-.295 * * *$ & -.071 & -.019 & $-.226 * * *$ & $-.182 * *$ & -.041 \\
\hline $\begin{array}{l}\text { Household } \\
\text { Income }\end{array}$ & $-.278 * * *$ & -.041 & $-.327 * * *$ & $-.302 * * *$ & $-.152 *$ & $-.202^{* *}$ & $-.287 * * *$ & -.077 \\
\hline Suicidality & $.366^{* * *}$ & $.267 * * *$ & $.211^{* *}$ & $.244 * * *$ & $.211 * *$ & $.156^{*}$ & $.139 *$ & $.382 * * *$ \\
\hline $\begin{array}{l}\text { Course of } \\
\text { Illness }\end{array}$ & $-.289 * * *$ & $-.153^{*}$ & $-.226 * * *$ & $-.295^{* *}$ & -.097 & $-.202 * *$ & $-.273 * * *$ & -.086 \\
\hline $\begin{array}{l}\text { Gender } \\
\text { (female) }\end{array}$ & -.112 & -.042 & $-.155^{*}$ & $-.169 *$ & -.089 & .061 & -.055 & -.025 \\
\hline Age & -.003 & .039 & -.077 & -.039 & .185 & -.019 & .056 & $-.157^{*}$ \\
\hline $\begin{array}{l}\text { PRQ85 } \\
\text { (Time 1) }\end{array}$ & $-.496 * * *$ & $-.248 * * *$ & $-.222 * * *$ & $-.546 * * *$ & $.178 *$ & $-.343 * * *$ & $-.361 * * *$ & $-.417 * * *$ \\
\hline
\end{tabular}

ANOVA indicated that self-rated severity of illness was related to PAIS-SR scores ( $F=15.41, p=.0000)$ with PAIS-SR scores increasing at more serious levels of sensitivity. The severe and disabled groups had significantly higher PAIS-SR scores (indicating more disruption) than the mildly and moderately affected groups $(p<.05)$ as indicated on the Scheffe Multiple Range Test.

A MANOVA conducted with severity level as the independent variable and the domain mean item scores as dependent variables was significant (Pillai's Criterion $=.4777, F=6.74, p<.001$ ). Follow-up univariate tests revealed the domains of Vocational Environment, Social Environment, Domestic Environment and Extended Family Relationships to be significantly associated with severity level (all $p<.001$ ) while Health Care Orientation, Sexual Domain, and Psychological Distress were not. 
Respondents who cited having lived in unusual circumstances such as tents or trailers had higher overall PAIS-SR scores than those who did not $(t=-3.46, p=.001)$. While having a physician educated about MCS was not significantly associated with overall PAIS-SR scores, Health Care Orientation Domain score was. Those with physicians deemed by respondents to be knowledgeable about MCS showed less negative attitudes toward their health care $(t=6.51, p<.001)$. Sample items from the Health Care Orientation subscale and responses are shown in Table 5, and can reveal more detail regarding attitudes toward health care in this group of respondents. For example, when asked about doctors and the quality of available health care, over half responded "I don't have much faith in doctors and medical care today".

Table 5. Responses to Health Care Orientation Individual Items in Percentages

In general, how do you feel about the quality of medical care available today and the doctors who provide it?

\begin{tabular}{|l|l|}
\hline a) Medical care has never been better, and the doctors who give it are doing an excellent job. & $1.0 \%$ \\
\hline $\begin{array}{l}\text { b) The quality of medical care available is very good, but there are some areas that could stand } \\
\text { improvement. }\end{array}$ & $40.9 \%$ \\
\hline c) Medical care and doctors are just not of the same quality they once were. & $5.0 \%$ \\
\hline d) I don't have much faith in doctors and medical care today. & $53.1 \%$ \\
\hline
\end{tabular}

During your present illness you have received treatment from both doctors and medical staff. How do you feel about them and the treatment you have received from them?

a) I am very unhappy with the treatment I have received and don't think the staff has done all they could have for me.

b) I have not been impressed with the treatment I have received, but I think it is probably the best they can do.

c) The treatment has been pretty good on the whole, although there have been a few problems.

d) The treatment and the treatment staff have been excellent.

$18.8 \%$

$39.3 \%$

$34.2 \%$

$7.7 \%$

\section{Longitudinal data for 209 respondents}

Participants rated their conditions (see Table 1 for rating criteria) as mild $(n=22)$, moderate $(n=73)$, severe $(n=79)$, or disabled $(n=33)$. Table 6 presents sample characteristics by level of self-rated severity of condition. Differences across severity levels were statistically significant for \% employed at initial data collection and at follow-up. For example, at the initial data collection, $86.4 \%$ of those rating their conditions as mild were working, compared to $3 \%$ of those who rated themselves as disabled. Working status differed by level of severity at time 1 from $72.7 \%$ of mild sufferers to $12.1 \%$ of those in the disabled category. Presumably, these occupational differences affected income, as differences in income are significant for personal income at both collection points, and for household income at initial collection. Gender, age and other demographics did not differ by level of severity. Nor did illness characteristics or medical costs (see Table 6). Of the psychosocial variables, levels of social support did not vary according to severity level, but psychosocial adjustment to illness did with PAIS-SR scores increasing with level of severity of condition. Additionally, only $4.5 \%$ of those with self-rated mild conditions at time 1 had seriously considered suicide, compared with $20.5 \%, 20.3 \%$, and $18.2 \%$ of the moderate, severe, and disabled categories respectively. Of the mild group, 9.1\% had made a plan or attempted suicide, compared with $11.0 \%, 12.7 \%$, and $18.2 \%$ of the moderate, severe, and disabled groups.

Persons rated their course of condition as worsened, stable or improved at time 1 and time 2. (In addition I added the category of mixed at time 2, as many respondents described "going up and down"). Table 7 presents course of condition at time 2 by course of condition at time 1 . Observed values were statistically significant from expected values (chi-square = $36.16, \mathrm{p}=.00000$ ) showing that course of condition at time 1 was not independent of course of condition two years later. Respondents who reported having worsened up to time one were more likely to continue to worsen and less likely to improve than expected. Of the 73 persons whose health had worsened up to time 1, 24 continued to worsen in the ensuing two years, 34 stayed the same or had a mixed course, and only 15 improved. In contrast, the group improving at time 1 showed more improvement and less worsening in the ensuing two years than expected by chance. Of those 102 who had improved since becoming chemically sensitive, only 7 worsened by time two, 45 stayed the same or had a mixed course, and 50 continued to improve. Those reporting a stable course at time one were more likely to remain stable. 
Table 6. Sample Characteristics by Severity of Condition

\begin{tabular}{|c|c|c|c|c|c|}
\hline & $\begin{array}{l}\text { Mild MCS } \\
\mathrm{N}=22\end{array}$ & $\begin{array}{l}\text { Moderate MCS } \\
\mathrm{N}=73\end{array}$ & $\begin{array}{l}\text { Severe MCS } \\
N=79\end{array}$ & $\begin{array}{l}\text { Disabled } \\
N=33\end{array}$ & $\begin{array}{l}\text { Mild vs Mod vs Sev vs Dis } \\
p \text { level }\end{array}$ \\
\hline Gender (\% women) & 86.4 & 82.2 & 83.5 & 75.8 & .73 \\
\hline Age at time 1 & 44.5 & 48.8 & 46.1 & 46.2 & .23 \\
\hline$\%$ employed at time 1 & 86.4 & 56.2 & 86.1 & 3.0 & $.00^{\mathrm{a}}$ \\
\hline \% employed at time 2 & 72.7 & 47.9 & 20.3 & 12.1 & $.00 \mathrm{~b}$ \\
\hline $\begin{array}{l}\% \text { in intimate } \\
\text { relationship at time } 1\end{array}$ & 63.6 & 58.9 & 67.9 & 66.7 & .69 \\
\hline $\begin{array}{l}\% \text { in intimate } \\
\text { relationship at time } 2\end{array}$ & 45.5 & 50.7 & 56.6 & 56.3 & .76 \\
\hline $\begin{array}{l}\text { Personal income at } \\
\text { Time } 1 \text { in thousands }\end{array}$ & 28.3 & 17.6 & 9.1 & 7.9 & $.00^{\mathrm{c}}$ \\
\hline $\begin{array}{l}\text { Personal income at } \\
\text { Time } 2 \text { in thousands }\end{array}$ & 27.4 & 21.1 & 12.2 & 10.24 & $.00^{\mathrm{d}}$ \\
\hline $\begin{array}{l}\text { Household income at } \\
\text { Time } 1 \text { in thousands }\end{array}$ & 52.6 & 40.3 & 29.0 & 35.2 & $.01^{\mathrm{e}}$ \\
\hline $\begin{array}{l}\text { Household income at } \\
\text { Time } 2 \text { in thousands }\end{array}$ & 40.0 & 43.0 & 31.3 & 35.6 & .18 \\
\hline \% citing 1 exposure & 40.0 & 41.2 & 55.8 & 60.6 & .10 \\
\hline $\begin{array}{l}\% \text { citing pesticide as } \\
\text { initial sensitizer }\end{array}$ & 22.2 & 18.8 & 25.5 & 18.2 & .84 \\
\hline Years ill & 15.1 & 16.1 & 13.6 & 13.6 & .65 \\
\hline Age became ill & 23.3 & 33.0 & 32.5 & 32.6 & .70 \\
\hline $\begin{array}{l}1 \text { year medical costs } \\
\text { in dollars }\end{array}$ & 3,208 & 4,672 & 5,527 & 10,670 & .14 \\
\hline $\begin{array}{l}\text { Total medical costs } \\
\text { in dollars }\end{array}$ & 11,973 & 34,987 & 39,854 & 36,099 & .71 \\
\hline Cost to redo home & 3,853 & 33,327 & 23,560 & 38,629 & .53 \\
\hline$\%$ with educated doctor & 68.2 & 69.4 & 75.9 & 84.8 & .34 \\
\hline PRQ85 score time 1 & 126.8 & 128.6 & 127.3 & 120.8 & .56 \\
\hline PRQ85 score time 2 & 124.6 & 128.5 & 139.6 & 125.2 & .58 \\
\hline PAIS-SR score time 1 & 54.4 & 60.9 & 71.38 & 75.27 & $.000^{\mathrm{f}}$ \\
\hline $\begin{array}{l}\text { \% lived in unusual } \\
\text { circumstances }\end{array}$ & 9.5 & 51.5 & 82.1 & 97.0 & $.00^{\mathrm{g}}$ \\
\hline
\end{tabular}

Notes. ${ }^{\mathrm{c}} F=12.99, p=.0000$; Tukey revealed mild significantly different from moderate, severe, and disabled. Moderate significantly different from both severe and disabled groups.

${ }^{\mathrm{d}} F=6.67, p=.0003$; Tukey revealed mild significantly different from severe and disabled. Moderate significantly different from severe and disabled.

${ }^{\mathrm{f}} F=15.41, p<.001$; Tukey revealed that mild significantly differed from severe and disabled. Moderate significantly differed from severe and disabled.

Table 7. Course of Condition at 2-Year Follow-up by Course of Condition at Time 1

\begin{tabular}{llll}
\hline \multirow{2}{*}{ Course of Condition up to time $\mathbf{1}$} & \multicolumn{2}{l}{ Course of Condition Time $\mathbf{1}$ to Time $\mathbf{2}$} & Improved \\
\cline { 2 - 4 } & Worsened & Stable/Mixed & $20.5 \%$ \\
\hline Worsened & $32.9 \%$ & $46.6 \%$ & $(\mathrm{n}=15)$ \\
$(\mathrm{n}=73$ & $(\mathrm{n}=24)$ & $(\mathrm{n}=34)$ & $14.3 \%$ \\
Stable/mixed & $0 \%$ & $85.7 \%$ & $(\mathrm{n}=2)$ \\
$(\mathrm{n}=14)$ & & $(\mathrm{n}=12)$ & $49.0 \%$ \\
Improved & $6.9 \%$ & $44.1 \%$ & $(\mathrm{n}=50$ \\
$(\mathrm{n}=102)$ & $(\mathrm{n}=7)$ & $(\mathrm{n}=45)$ & 5 \\
\hline
\end{tabular}

Note. Chi-squared value $($ Pearson $)=36.16(\mathrm{df}=4)$

$$
p=.00000
$$

Published by Sciedu Press 
Table 8. Course of Condition at 2-Year Follow-Up by Severity of Condition at Time 1

\begin{tabular}{llll}
\hline \multirow{2}{*}{ Severity At time 1 } & \multicolumn{2}{l}{ Course of Condition Time $\mathbf{1}$ to Time 2 } & Improved \\
\cline { 2 - 4 } & Worsened & Stable/Mixed & $31.8 \%$ \\
\hline Mild & $18.2 \%$ & $50.0 \%$ & $(\mathrm{n}=7)$ \\
$(\mathrm{n}=22)$ & $(\mathrm{n}=4)$ & $(\mathrm{n}=11)$ & $37.0 \%$ \\
Moderate & $6.8 \%$ & $56.2 \%$ & $(\mathrm{n}=27)$ \\
$(\mathrm{n}=73)$ & $(\mathrm{n}=5)$ & $(\mathrm{n}=41)$ & $32.1 \%$ \\
Severe & $21.9 \%$ & $46.2 \%$ & $(\mathrm{n}=25)$ \\
$(\mathrm{n}=78)$ & $(\mathrm{n}=17)$ & $(\mathrm{n}=36)$ & $34.4 \%$ \\
Disabled & $31.3 \%$ & $34.4 \%$ & $(\mathrm{n}=11)$ \\
\hline
\end{tabular}

Note. Chi-square Pearson value $(\mathrm{df}=6)=11.6, p=.07$

Table 9. Sample Characteristics by Course of Condition at 2-Year Follow-Up $(n=209)$

\begin{tabular}{|c|c|c|c|c|}
\hline & $\begin{array}{l}\text { Worsened } \\
\text { Course } \\
\mathbf{n}=36\end{array}$ & $\begin{array}{l}\text { Same/Mixed } \\
\text { Course } \\
\mathbf{N}=99\end{array}$ & $\begin{array}{l}\text { Improved } \\
\text { Course } \\
\mathrm{N}=72\end{array}$ & $\begin{array}{l}\text { Worsened vs } \\
\text { Same/Mixed vs } \\
\text { Improved p level }\end{array}$ \\
\hline Gender (\% women) & 77.8 & 79.8 & 87.5 & .33 \\
\hline Age at time 2 & 51.4 & 49.3 & 46.9 & \\
\hline \% Employed at time 1 & 27.8 & 37.4 & 34.7 & .59 \\
\hline \% Employed at time 2 & 19.4 & 38.4 & 36.1 & .11 \\
\hline $\begin{array}{l}\% \text { in intimate relationship } \\
\text { at time } 1\end{array}$ & 55.6 & 63.3 & 69.4 & .35 \\
\hline$\%$ in intimate relationship at time 2 & 13.9 & 44.4 & 41.7 & .04 \\
\hline Personal income at Time 1 in thousands & 12.6 & 14.6 & 13.9 & .83 \\
\hline Personal income at Time 2 in thousands & 11.7 & 17.0 & 17.9 & .26 \\
\hline Household income at Time 1 in thousands & 38.1 & 34.5 & 40.5 & .48 \\
\hline Household income at Time 2 in thousands & 25.3 & 35.2 & 45.4 & $.01^{\mathrm{a}}$ \\
\hline \% citing 1 exposure as initial sensitizer & 67.6 & 46.2 & 43.7 & .07 \\
\hline \% citing pesticide as initial sensitizer* & 33.3 & 21.3 & 21.9 & .47 \\
\hline Years ill & 16.1 & 17.0 & 10.7 & $.00^{\mathrm{b}}$ \\
\hline Age became ill & 33.3 & 30.4 & 34.5 & .12 \\
\hline 1-year medical costs in dollars & 10,291 & 4,444 & 6,141 & .14 \\
\hline Total medical costs in dollars & 36,569 & 28,184 & 43,170 & .48 \\
\hline Cost to make home safe in dollars & $73,845^{* *}$ & 22,808 & 14,937 & $.00^{\mathrm{c}}$ \\
\hline$\%$ who had doctor educated re MCS & 80.6 & 67.3 & 79.2 & .13 \\
\hline PRQ85 score Time 1 & 125.3 & 121.2 & 134.7 & $.00^{\mathrm{d}}$ \\
\hline PRQ85 score Time 2 & 127.9 & 129.7 & 136.7 & .72 \\
\hline PAIS-SR score Time 1 & 71.5 & 67.5 & 58.6 & $.00^{\mathrm{e}}$ \\
\hline
\end{tabular}

Notes. * of those who reported one identifiable exposure

${ }^{\mathrm{a}} F=4.66, p=.01$. Tukey revealed that those who improved had significantly higher income than those who worsened.

${ }^{\mathrm{b}} F=5.10, p=.0069$. Tukey revealed that those who had stable/mixed course had been ill longer than those who improved.

${ }^{\mathrm{c}} F=5.89, p=.0034$. Tukey revealed that the worsened group had spent significantly more money than the stable/mixed course group or the improved group.

** However, one outlier in the worsened group who had spent $\$ 800,000$ may have accounted for this.

${ }^{\mathrm{d}} F=5.84, p=0034$. Tukey revealed that those who improved scored significantly higher than those who had a stable/mixed course.

${ }^{\mathrm{e}} F=7.65, p=.0006$. Tukey revealed that both the worsened and stable/mixed groups scored significantly higher than improved group.

Sample characteristics were examined by course of condition between time 1 and time 2 . Table 9 presents these results. No demographics differed significantly between those who had worsened, been stable or mixed, or improved in condition. Among income measures, only household income at time two was significant at the .01 level. Groups did differ in number of years ill with those who had worsened reporting conditions lasting 16.1 years, those stable/mixed 17 years, and those 
who improved only 10.7 years. The groups differed in costs of making their homes safe, and those who had worsened had spent more money altering their homes, but one outlier may have accounted for these results. Of the psychosocial variables, groups differed in social support at time 1 with those who improved having a higher level of support than those who had a stable/mixed course. Earlier measures of psychosocial adjustment differed significantly also with the improved groups having had better earlier adjustment than the worsened and stable/mixed course groups. No differences emerged in social support at time 2 .

Participants' course of condition at time two was also examined by severity of condition at time one. Table 8 presents these results. Observed counts in each category were not statistically significantly different from expected values (chi-square $=$ 11.6, $p=.07$ ). It appeared that this analysis approached significance due to the tendency for less of the moderately sensitive individuals and more of the disabled respondents than expected to worsen. However, course of condition up to initial data collection was more indicative of course in the ensuing two years than was initial severity.

\section{Discussion}

Persons self-reporting MCS represent men and women of varying ages and relationship statuses, and from a very large number of occupations. Persons report becoming sensitized in a variety of conditions through exposure to a number of chemicals. Employment and income suffered at increasingly severe levels of sensitivity. Persons with declining health at initial data collection were more likely to worsen or stay the same than those who had managed to initiate improvement. This underscores the importance of finding ways to help persons intervene in their health and prevent the commonly reported spread of sensitivities (the "spreading phenomenon") ${ }^{[26]}$.

Consistent with the findings of Lavergne and colleagues ${ }^{[27]}$ better psychosocial adjustment to illness for this sample was associated with greater income and a less severe condition. Also better adjustment was associated with higher levels of social support, higher education, and an improved course if illness. On the other hand, total PAIS-SR scores did not correlated significantly with age, gender, or length of illness.

Persons with more severe conditions had poorer overall psychosocial adjustment to illness. The increased disruption in Social and Vocational Environments in this study is consistent with other studies of life impacts for persons with MCS ${ }^{[17,28]}$. The Extended Family Relations scale was less disrupted in this study and this corresponds with the findings of White and colleagues ${ }^{[29]}$ in a sample of 158 diabetic women. However, relations with extended family, as well as with immediate family and friends were increasingly affected as severity of condition increased. Occupation also was more highly impacted at increasing levels of severity and this is consistent with findings of Gibson and Lindberg ${ }^{[30]}$ regarding difficulties with receiving job accommodations and frequent loss of livelihood. If job, family, and social contacts are the realms most affected by increasingly severe MCS, they may provide appropriate points of entry for prevention or early intervention efforts targeted at those reporting mild or early stages of MCS. Job accommodation, family support and community access will aid people in negotiating their social geographies ${ }^{[31]}$. Crooks et al. ${ }^{[31]}$ cite the struggles over access to place for those with disabilities as they negotiate their social geographies. Clearly stated by Fox and Kim ${ }^{[32]}$ in their study of persons with MCS, "The barriers faced by individuals from emerging disability groups often prevent experiencing the benefits of participation in society" (p. 325). Health care professionals can provide support and advocacy for patients who have difficulties in acquiring cooperation or support from co-workers, family, and the community, thus preserving their access and preventing the spread of sensitivities that often results from continual chemical exposure in sensitized persons. For example, Chircop and Keddy ${ }^{[33]}$ found that women with MCS reported often enduring chemical exposures indirectly from family members who failed to make accommodations. Nurses and health care advocates could intervene in the family system to prevent such occurrences.

Though researchers have used the PAIS-SR to study MCS ${ }^{[34]}$, some underlying assumptions regarding the instrument pose methodological problems for use with this population. For example, one assumption is that adequate medical treatment 
exists for the illness studied. But participants in this study left blank some of the questions about medical treatment based on this assumption. Given the controversies regarding conceptualization of and treatment for MCS, and the scarcity of providers who treat it, this may not be an appropriate assumption to apply to measuring attitude toward health care in those in MCS. Although most persons in this study had physicians whom were regarded as educated about MCS, persons had gone through numerous others perceived not to be educated before contacting their present provider. Since a high score on the Health Care Orientation Domain is assumed to reflect a cynical attitude toward providers, this score should probably be interpreted with caution when testing this population. Recognition that more controversy than treatment exists regarding your condition may be a sign of education or good reality testing rather than an indicator of cynicism. The PAIS-SR also assumes that providers have given patients appropriate medical information about their condition, which may be the case for most physical conditions. However, patients with MCS may have to educate themselves and struggle for diagnosis ${ }^{[21]}$ in the absence of medical consensus about their condition.

Responses to the questions about unmet medical needs illustrate the inaccessibility of our health care system for persons with MCS. Chemical barriers, medical personnel's lack of training regarding MCS, perfumes and other fragrances in medical offices, and the risks of anesthesia were all cited as barriers to receiving adequate health care. This subset of the population appears therefore to lack health care for serious medical needs. Participants reported coping through the use of alternative providers, educating their current providers, or delaying or avoiding medical treatment. Some participants received safe care from alternative practitioners, and some used alternative anesthetics such as acupuncture or hypnosis for surgeries. Some were able to collaborate with their providers to find solutions to health care barriers and thus receive the needed interventions. Some who avoided treatment experienced symptom exacerbation or even endangered their lives if problems escalated into emergencies, indicating that this is a crucial problem for further study if health care is to be accessible to persons with chemical sensitivities. Ishikawa and Miyata ${ }^{[35]}$ called for training of health care providers, cooperation with health care centers, and creation of a database on MCS literature among other actions. Larsson and Martensson ${ }^{[36]}$ emphasized the need to acquaint health care providers with the condition in order to help patients gain comfort. As Imai and colleagues ${ }^{[37]}$ admonished, "A delay of measures means prolonged exposure to the chemicals. Therefore, in Japan, all hospitals must become capable of diagnosing and treating SHS and MCS and it is necessary to diffuse knowledge about the disorder among medical professionals immediately” (p. 106).

\section{Conclusions}

Persons with MCS experience a range in severity of symptoms, considerable psychosocial impact from their condition, and, having entered a period of worsening health, tend to continue to do poorly. Those whose conditions are severe suffer disruption in job, social life, home environment, and extended family. In fact, persons at the disabled end of the spectrum are most likely unable to work and some become caught in a downhill spiral of economic loss that leads to homelessness. Informed health care is crucial for this population in order to avoid the decline in health and poor attitude toward health care professionals associated with not having a knowledgeable provider. Nursing professionals can fill a large gap in understanding that exists in the healthcare system regarding chemical sensitivity and some discussion of the problem in nursing education can insure that availability of professionals familiar with the needs of this population improves. In addition, nursing professionals can strive to make their premises accessible for persons with CS by using safer alternatives to toxic pesticides, fragrances, air fresheners, and cleaning products. Recognition that a patient with MCS has most probably had a difficult struggle in multiple life arenas, including that of health care, can open the door to positive communication and a respectful patient-provider relationship.

\section{References}

[1] Bloch RM, Meggs WJ. Comorbidity patterns of self-reported chemical sensitivity, allergy, and other medical illnesses with anxiety and depression. Journal of Nutritional \& Environmental Medicine. 2007; 16(2): 136-148.

http://dx.doi.org/10.1080/13590840701352823 
[2] Millqvist E, Bende M, Löwhagen O. Sensory hyperreactivity - a possible mechanism underlying cough and asthma-like symptoms. Allergy. 1998; 53: 1208-1212. http://dx.doi.org/10.1111/j.1398-9995.1998.tb03843.x

[3] Nordin S, Millqvist E, Löwhagen O. A short chemical sensitivity scale for assessment of airway sensory hyperreactivity. International Archives of Occupational and Environmental Health. 2004; 77: 249-254. PMid:15024570 http://dx.doi.org/10.1007/s00420-004-0504-7

[4] Ternesten-Hasséus E, Lowhagen O, Millqvist E. Quality of life and capsaicin sensitivity in patients with airway symptoms induced by chemicals and scents: A longitudinal study. Environmental Health Perspectives. 2007; 115(3): 425-429. PMid:17431493 http://dx.doi.org/10.1289/ehp.9624

[5] Hausteiner C, Bornschein S, Hansen J, Zilker T, Förstl H. Self-reported chemical sensitivity in Germany: A population-based survey. International Journal of Hygiene and Environmental Health. 2005; 208: 271-278. PMid:16078641 http://dx.doi.org/10.1016/j.ijheh.2005.03.006

[6] Swoboda DA. The social construction of contested illness legitimacy: A grounded theory analysis. Qualitative Research in Psychology. 2006; 3: 233-251. http://dx.doi.org/10.1191/1478088706qrp061oa

[7] Gibson PR. Elms ANM, Ruding LA. Perceived treatment efficacy for conventional and alternative therapies reported by persons with multiple chemical sensitivity. Environmental Health Perspectives, 2003. 111: 1498-1504. http://dx.doi.org/10.1289/ehp.5936

[8] Lipson JG. Multiple chemical sensitivities: Stigma and social experiences. Medical Anthropology Quarterly. 2004; 18(2): 200-213. http://dx.doi.org/10.1525/maq.2004.18.2.200

[9] Gibson PR, Vogel VM. Sickness related dysfunction in persons with self-reported multiple chemical sensitivity at four levels of severity. Journal of Clinical Nursing. 2007; 18: 72-81.

[10] Hojo S, Ishikawa S, Kumano H, Miyata M, Sakabe K. Clinical characteristics of physician-diagnosed patients with multiple chemical sensitivity in Japan. International Journal of Hygiene and Environmental Health, 2008; 211(5-6): 682-689. PMid:18155642 http://dx.doi.org/10.1016/j.ijheh.2007.09.007

[11] Andersson L, Johansson A, Millqvist E, Nordin S, Bende M. Prevalence and risk factors for chemical sensitivity and sensory hyperreactivity in teenagers. International Journal of Hygiene and Environmental Health. 2008; 211(5-6): 690-697. PMid:18403259 http://dx.doi.org/10.1016/j.ijheh.2008.02.002

[12] Johansson Å, Brämerson A, Millqvist E, Nordin S, Bende M. Prevalence and risk factors for self-reported odour intolerance: the Skövde population-based study. International Archives of Occupational and Environmental Health. 2005; 78: 559-564. PMid:16001204 http://dx.doi.org/10.1007/s00420-005-0616-8

[13] Berg ND, Linnegarg A, Dirksen A, Elberling J. Prevalence of self-reported symptoms and consequences related to inhalation of airborne chemicals in a Danish population. International Archives of Occupational and Environmental Health. 2008; 81: 881-887. PMid:18058120 http://dx.doi.org/10.1007/s00420-007-0282-0

[14] Meggs WJ, Dunn KA, Bloch RM, Goodman PE, Davidoff AL. Prevalence and nature of allergy and chemical sensitivity in a general population. Archives of Environmental Health. 1996; 51(4): 75-82.

[15] Caress S, Steinemann A. Prevalence of fragrance sensitivity in the American population. Journal of Environmental Health. 2009; 71(7): 46-50, 2009.

[16] Bell IR, Schwartz GE, Peterson JM, Amend D. Self-reported illness from chemical odors in young adults without clinical syndromes or occupational exposures. Archives of Environmental Health. 1993; 48(1): 6-13. PMid:7680851 http://dx.doi.org/10.1080/00039896.1993.9938387

[17] Gibson PR, Cheavens J, Warren ML. Multiple chemical sensitivity/environmental illness and life disruption. Women \& Therapy. 1996; 19: 63-79.

[18] Miller CS, Mitzel HC. Chemical sensitivity attributed to pesticide exposure versus remodeling. Archives of Environmental Health. 1995; 50(2): 119-129. PMid:7786048 http://dx.doi.org/10.1080/00039896.1995.9940889

[19] Engel LR, Gibson PR, Adler ME, Rice, VM. Unmet medical needs in persons with self-reported multiple chemical sensitivity. Poster delivered at the Annual Meeting of the Southeastern Psychological Association, Norfolk, Virginia, March 20-23, 1996.

[20] Doiron N. People with environmental sensitivities: Life, identity, and services. Doctoral Thesis in Social Work, 2007, University of Toronto.

[21] Dumit J. Illnesses you have to fight to get: Facts as forces in uncertain, emergent illnesses. Social Science \& Medicine, 2006; 62: 577-590. PMid:16085344 http://dx.doi.org/10.1016/j.socscimed.2005.06.018

[22] Weinert C. A social support measure: PRQ85. Nursing Research, 1987; 36: 273-277. PMid:3306610

[23] Weinert C, Tilden VP. Measures of social support: Assessment of validity. Nursing Research, 1990; 39: 212-216. PMid:2367200

[24] Derogatis LR. (The psychosocial adjustment to illness scale (PAIS). Journal of Psychosomatic Research, 1986; 30(1): 77-91. http://dx.doi.org/10.1016/0022-3999(86)90069-3

[25] E.I. Disability Classification. The Human Ecologist, 1987; 35: 13. 
[26] Ashford NA, Miller CS. Chemical Exposures: Low Levels and High Stakes. Second Edition. New York: Van Nostrand Reinhold, 1998.

[27] Lavergne MR, Cole DC, Kerr K, Marshall LM. Functional impairment in chronic fatigue syndrome, fibromyalgia, and multiple chemical sensitivity. Canadian Family Physician, 2010; 56: 57-65.

[28] Vierstra CV, Rumrill PD, Koch LC, McMahon BT. Multiple chemical sensitivity and workplace discrimination: The national EEOC ADA research project. Work. 2007; 28: 391-402. PMid:17522460

[29] White NE, Richter JM, Fry C. Coping, social support, and adaptation to chronic illness. Western Journal of Nursing Research. 1992; 12: 211-224. http://dx.doi.org/10.1177/019394599201400208

[30] Gibson PR, Lindberg A. Work accommodation for people with multiple chemical sensitivity. Disability \& Society. 2007; 22(7): 717-732. http://dx.doi.org/10.1080/09687590701659576

[31] Crooks VA. Chouinard V, Wilton RD. Understanding, embracing, rejecting: Women's negotiations of disability constructions and categorizations after becoming chronically ill. Social Science \& Medicine. 2008; 67: 1837-1846. PMid:18760870 http://dx.doi.org/10.1016/j.socscimed.2008.07.025

[32] Fox M, Kim K. Understanding emerging disabilities. Disability \& Society, 2004; 19(4): 323-3336. http://dx.doi.org/10.1080/09687590410001689449

[33] Chircop A, Keddy B. Women living with environmental illness. Health Care for Women International. 2003; 24: 371-383. PMid:12916143

[34] Fiedler N, Maccia C, Kipen H. Evaluation of chemically sensitive patients. Journal of Occupational Medicine. 1992; 34: 529-538. PMid:1593293

[35] Ishikawa S, Miyata M. Chemical sensitivity and its clinical characteristics in Japan. Asian Medical Journal. 2000; 43(1): 7-15.

[36] Larsson C, Martensson L. Experiences of problems in individuals with hypersensitivy to odours and chemicals. Journal of Clinical Nursing. 2009; 18: 737-744. PMid:19239540 http://dx.doi.org/10.1111/j.1365-2702.2008.02599.x

[37] Imai N, Imai Y, Kido Y. Psychosocial factors that aggravate the symptoms of sick house syndrome in Japan. Nursing and Health Sciences. 2009; 10: 101-109. PMid:18466382 http://dx.doi.org/10.1111/j.1442-2018.2008.00389.x 